\title{
Interstitial fibrosis in papillary thyroid microcarcinoma and its association with biological behavior
}

\author{
XUN LIU ${ }^{1}$, SHUAI ZHANG ${ }^{1}$, QINWEI GANG ${ }^{2}$, SHIKAI SHEN ${ }^{2}$, JIAN ZHANG $^{1}$, \\ YU LUN ${ }^{1}$, DONGDONG XU ${ }^{1}$, ZHIQUAN DUAN ${ }^{1}$ and SHIJIE XIN ${ }^{1}$ \\ ${ }^{1}$ Department of Vascular and Thyroid Surgery, The First Hospital of China Medical University, Shenyang, Liaoning 110001; \\ ${ }^{2}$ Department of General Surgery, The People's Hospital of Liaoning, Shenyang, Liaoning 110016, P.R. China
}

Received November 24, 2016; Accepted November 10, 2017

DOI: $10.3892 / \mathrm{ol} .2018 .7928$

\begin{abstract}
Previous studies have revealed that fibrosis may affect the biological behavior of tumors, however associated research on papillary thyroid microcarcinoma (PTMC) is rare. The aim of the present study was to explore the association between interstitial fibrosis (IF) and the biological behavior of PTMC. In the present study, a total of 511 consecutive cases of PTMC were evaluated for the presence of IF and its association with clinical parameters and pathologic biomarkers. IF was identified in 340 of the 511 consecutive cases and it was significantly associated with the age $(\mathrm{P}=0.033)$, tumor diameter $(\mathrm{P}=0.017)$ and lymphocytic metastasis $(\mathrm{P}<0.001)$ of the patient. There were significantly more female in the fibrosis group than in fibrosis-absent group $(\mathrm{P}=0.024)$. In the analysis of clinical biomarkers using immunohistochemistical staining, IF was significantly associated with cytokeratin $19(\mathrm{P}=0.008)$ and galectin-3 $(\mathrm{P}=0.022)$. Analysis of patient outcomes indicated that IF was an independent prognostic factor of recurrence (hazard ratio $=2.181 ; 95 \%$ confidence interval $=1.163-4.090 ; \mathrm{P}=0.015)$. These findings suggest that the combined effect of a patient's age, sex and tumor size may potentially contribute to fibrotic lesions and IF was a factor contributing to poor prognosis in patients with PTMC.
\end{abstract}

\section{Introduction}

Papillary thyroid carcinoma (PTC) represents $~ 90 \%$ of differentiated thyroid carcinomas in Japan (2004), which are the most common malignant tumors of the endocrine system (1). Papillary thyroid microcarcinoma (PTMC) is defined as PTCs with a diameter of $<10 \mathrm{~mm}$, and account for $39.5 \%$ of all PTCs in Italy (between 1993 and 2002) (2). Certain factors including radiation exposure, iodine deficiency and a family

Correspondence to: Dr Jian Zhang, Department of Vascular and Thyroid Surgery, The First Hospital of China Medical University, 155 Nanjing Bei Street, Shenyang, Liaoning 110001, P.R. China E-mail: jianzhang@cmu.edu.cn

Key words: papillary thyroid microcarcinoma, interstitial fibrosis, cancer-associated fibroblasts history of PTCs are associated with tumorigenesis and prognosis; however, the expression status of specific biomarkers, including galectin-3 and cytokeratin 19 (CK19) may also be used to predict tumor progression $(3,4)$.

PTMC grows slowly without obvious symptoms, however due to the increased ultrasound detection rate, the incidence rate of PTMC has been rising gradually in recent years (5). The majority of PTMCs are identified by accident or are combined with other thyroid diseases (6). PTMCs may be standardly diagnosed by removing thyroid lesions and observing their pathological features and by immunohistochemistry staining of biomarkers (for example galectin-3, CK-19 and TTF-1) (7-9). Surgical treatment may lead to a favorable prognosis for PTMC; however, due to the low risk of papillary thyroid cancer, various postoperative treatments have little effect on prognostic outcome, and to the best of our knowledge no previous studies have identified which therapeutic method is the best option (10). Certain PTMCs are more malignant compared with others and have a poor prognosis with early-stage lymphocytic metastasis $(11,12)$. These highly malignant tumors may be associated with multilocus-tumors, tumor size and dilation of a thyroid cyst (2,13-15).

Interstitial fibrosis (IF), which is composed of fibroblasts and a variable number of collagen fibers, has been observed in numerous malignant cancers (16-20). This suggests that IF may be a factor associated with tumor prognosis. In previous studies (21-23), fibrosis appears to be associated with an increased cancer recurrence rate and mortality. Previous observations have suggested that dense fibrosis may be another vital indicator for the diagnosis of PTC (24), however, few studies have focused on the associations between IF and PTC. Therefore, the aim of the present study is to perform a retrospective analysis of the clinical parameters and biomarkers of PTC and to determine the association and interactions between IF and PTMC.

\section{Materials and methods}

Patients. A total of 511 patients were recruited into the present study from the First Hospital of China Medical University (Shenyang, China), between January 2009 and December 2013; 340 patients were diagnosed with PTMC with IF and 171 patients were diagnosed with PTMC without 
IF. In total, $78.86 \%$ (304) of patients were female, $21.14 \%$ were male. The age range was 20-75 years, with an mean age of $46.83 \pm 10.69$. All patients underwent a thyroidectomy and met the following criteria: i) Diagnosed with PTMC according to pathological standards (25); ii) did not receive steroids or drugs that may induce fibrosis; and iii) did not present with any other disease than PTMC. Patients who had PTMC combined with thyroid inflammation or systemic diseases were excluded from the study. The present study was approved by the Institutional Review Board of China Medical University and by the First Hospital of China Medical University Medical Research Ethics Committee (Shenyang, China). Written informed consent was obtained from all patients prior to their inclusion within the present study.

All patients were divided into 2 groups. The experimental group was composed of patients with IF $(n=340)$ and the control group was composed of patients without IF $(n=171)$. Patients with IF were defined as having a fibrotic area composed of fibroblasts and collagen fibers within the tumor, which occupied the central part of the tumor and formed a radially expanding fibrosclerotic core. The patient's baseline characteristics, including age, sex, calcification, serum thyroid-stimulating hormone (TSH) level, tumor size, tumor node and metastasis stage, tumor multiplicity, bilaterality, extrathyroidal extension (ETE), subtype of papillary microcarcinoma and lymphocytic metastasis, were evaluated. The thyroid tumor stage was classified in accordance with the American Joint Committee on Cancer (26). Postoperative follow-up ended on 1st September 2016.

Histopathology. Each specimen slice was stained with hematoxylin and eosin for observing the pathological form of the cancer tissue. Freshly resected specimens, $\sim 1 \mathrm{~cm}$ in thickness, were fixed in $10 \%$ neutral formaldehyde for $12 \mathrm{~h}$ and then dehydrated using graded series of analytical pure ethanol at room temperature as follows: $60 \%$ (1 h), 75\% (30 min), 80\% (15 min), 95\% (10 $\mathrm{min}), 100 \%$ (5 min), then the specimens were placed in xylene at room temperature (10 $\mathrm{min} \times 2)$, and immersed in paraffin (efficient slice paraffin, melting point $56-58^{\circ} \mathrm{C}$ ) at $59^{\circ} \mathrm{C}$ for $1 \mathrm{~h}$, embedded in paraffin and cooled at room temperature. Paraffin specimens were then cut into $4 \mu \mathrm{m}$ slices, dewaxed using xylene (15 min x 2) and hydrated using graded series of analytical pure ethanol at room temperature as follows: $100 \%$ (5 min x 2), 95, 85 and 75\% ethanol ( 3 min each). Specimens were then stained with hematoxylin for $8 \mathrm{~min}$ at room temperature, followed by washing with $1 \%$ hydrochloric acid alcohol for a few seconds and then washed with tap water for $10 \mathrm{~min}$. Specimens were then stained with eosin for $5 \mathrm{~min}$ at room temperature, and then specimens were dehydrated using a graded series of ethanol at room temperature as follows: 75,85 and $95 \%$ ( 2 min each), $100 \%$ (1 $\min \times 2$ ); transparent in xylene at room temperature (5 min x 2); neutral gum (cat no., G8590; Solarbio, Beijing, China) sealed slice. Light microscopy was used to observe specimens (magnification, x100). The immunohistochemistry of all slices was performed by a minimum of 2 pathologists from the Pathology Department of the First Hospital of China Medical University and each experiment was repeated 3 times to confirm results. All cases were classified according to multiple clinical biomarkers, including cellular tumor antigen $\mathrm{p} 53$, proliferation marker protein $\mathrm{Ki}-67$ (Ki-67), CK19, thyroglobulin (Tg), thyroid transcription factor
I (TTF-1) and galectin-3. These biomarkers are used for the common diagnosis of PTMC, p53 and Ki67 positive samples may exhibit the proliferation of tumor cells, while CK19, TTF-1, Tg and galectin-3 positive samples may predict that the origin of the malignant cells is the thyroid epithelium.

Immunohistochemistry. Paraffin embedded sections ( $4 \mu \mathrm{m}$-thick) were dewaxed and hydrated as aforementioned. Specimens were then washed with phosphate-buffered saline (PBS), citric acid heat antigen repair for 2 min, incubated with $3 \%$ hydrogen peroxide for blocking endogenous peroxidase for $10 \mathrm{~min}$ at room temperature, washed with PBS, then incubated with primary antibodies at room temperature for $60 \mathrm{~min}$. Negative control specimens were incubated with PBS instead of the primary antibody. All antibodies were produced by Fuzhou Maixin Biotech Co., Ltd. (Fujian, China), and were supplied at ready-to-use dilutions. The primary antibodies $(100 \mu \mathrm{l})$ used were as follows: Galectin-3 (cat. no. MAB-0572), CK19 (cat. no. Kit-0030), TTF-1 (cat. no. MAB-0599), Ki-67 (cat. no. Kit-0005), p53 (cat. no. Kit-0010) and Tg (cat. no. MAB-0161). Sections were then washed with PBS 3 times and incubated with enzyme-labeled goat anti-mouse/rabbit immunoglobulin G polymer at room temperature (cat. no. KIT-5030) for $15 \mathrm{~min}$, and then washed with PBS. Following this, DAB (cat. no. DAB-1031; Fuzhou Maixin Biotech Co., Ltd.) was added for 3-5 min at room temperature for color development to assist in light microscopy analysis (magnification, x100), and then washed with tap water for $10 \mathrm{~min}$. Finally, specimens were stained with hematoxylin for $8 \mathrm{~min}$ at room temperature, washed with tap water, and the procedure of dehydration and transparency was the same as aforementioned. Neutral gum was used to seal the slice. Specimens were observed using light microscopy. IF was determined using 2 pathologists who were blinded to the study aims. Each experiment was repeated three times.

Statistical analysis. Data analysis was performed using SPSS (version 20; IBM Corp., Armonk, NY, USA). Continuous data were presented as the mean \pm standard deviation. Dichotomous variables were compared using the $\chi^{2}$ test or Fisher's exact test, while the Student's t-test was used to compare continuous variables. The survival data were analyzed using Kaplan-Meier curves and the log-rank test and Cox proportional hazard models. $\mathrm{P}<0.05$ was considered to indicate a statistically significant difference.

\section{Results}

Differences between PTMC with IF and without IF. There were 511 cases of PTMC examined in the present study. Patients with IF accounted for $66.54 \%$ (340 cases), while patients without IF accounted for $33.46 \%$ (171 cases) of the cases. The differences between PTMC and normal thyroid tissue in a fibrotic formation may be observed in Fig. 1. In Fig. 1A, the normal follicular structure interrupted by squashed cancer cells, accompanied by the proliferation of fibroblasts and collagen fibers. Fig. 1B demonstrates the complete thyroid follicular structure in the nodular goiter tissue with IF, collagen fibers are positioned next to the follicles. Diffuse collagen fibers appear next to the nodular goiter and there is almost no fibroblast proliferation. 
Table I. Characteristics of patients with PTMC with or without IF.

\begin{tabular}{|c|c|c|c|c|}
\hline Characteristic & PTMC with IF (\%) & PTMC without IF (\%) & Total $(\%)$ & P-value \\
\hline Age (years) & & & & 0.0331 \\
\hline Mean \pm SD & $47.81 \pm 10.44$ & $44.88 \pm 10.94$ & $46.83 \pm 10.69$ & \\
\hline Range & $21-75$ & $20-68$ & $20-75$ & \\
\hline$<45$ & $120(35.29)$ & $80(46.78)$ & $200(39.13)$ & \\
\hline$\geq 45$ & $220(64.71)$ & $91(53.22)$ & $311(60.87)$ & 0.012 \\
\hline \multicolumn{5}{|l|}{ Sex } \\
\hline Female & $278(81.77)$ & $125(73.10)$ & $403(78.86)$ & 0.0236 \\
\hline Male & $62(18.23)$ & $46(26.9)$ & $108(21.14)$ & \\
\hline Calcification & & & $511(80.44)$ & 0.3889 \\
\hline Present & $261(76.76)$ & $137(80.12)$ & $398(77.89)$ & \\
\hline Absent & $79(23.24)$ & 34 (19.88) & $113(22.11)$ & \\
\hline TSH (mmol/l) & & & & 0.863 \\
\hline Mean \pm SD & $1.76 \pm 1.49$ & $1.78 \pm 1.343$ & $1.77 \pm 1.44$ & \\
\hline Range & $0.002-10.43$ & $0.0020-7.61$ & $0.002-10.44$ & \\
\hline Tumor size (mm) & & & & 0.0136 \\
\hline Mean \pm SD & $4.93 \pm 2.46$ & $4.21 \pm 2.27$ & $4.69 \pm 2.42$ & \\
\hline Range & $0.5-10$ & $0.6-9$ & $0.5-10$ & \\
\hline Diameter $\geq 5 \mathrm{~mm}$ & $201(59.12)$ & $82(47.95)$ & $283(55.38)$ & 0.0166 \\
\hline Diameter $<5 \mathrm{~mm}$ & $139(40.88)$ & $89(52.05)$ & $228(44.62)$ & \\
\hline Multiplicity & & & & 0.2595 \\
\hline Absent & $262(77.06)$ & $124(72.51)$ & $386(75.54)$ & \\
\hline Present & 78 (22.94) & 47 (27.49) & $125(24.46)$ & \\
\hline Bilaterality & & & & 0.6463 \\
\hline Absent & $301(88.53)$ & $149(87.13)$ & $450(88.06)$ & \\
\hline Present & $39(11.47)$ & $22(12.87)$ & $61(11.94)$ & \\
\hline ETE & & & & 0.1322 \\
\hline Absent & $290(85.29)$ & $154(90.06)$ & 444 (86.89) & \\
\hline Present & $50(14.71)$ & 17 (9.94) & 67 (39.18) & \\
\hline Subtype & & & & 0.7377 \\
\hline Classic papillary & $326(95.88)$ & 165 (96.49) & 491 (96.07) & \\
\hline Follicular & $14(4.12)$ & $6(3.51)$ & $20(3.93)$ & \\
\hline Lymph metastasis & & & & 0.0003 \\
\hline LM present & $116(34.18)$ & 32 (18.71) & $148(28.96)$ & \\
\hline LM absent & $224(65.72)$ & $139(81.29)$ & $363(65.17)$ & \\
\hline Lymph node status & & & & 0.0058 \\
\hline N0 & $226(66.47)$ & 137 (80.12) & $363(71.04)$ & \\
\hline N1a & 74 (21.76) & 22 (12.87) & 96 (18.78) & \\
\hline N1b & $40(11.77)$ & $12(7.02)$ & $52(30.41)$ & \\
\hline TNM stage & & & & 0.0067 \\
\hline I & $278(81.76)$ & 159 (92.98) & $437(85.52)$ & \\
\hline III & 37 (10.88) & $8(4.68)$ & $45(8.81)$ & \\
\hline IV & $21(3.53)$ & $4(2.34)$ & $25(4.89)$ & \\
\hline
\end{tabular}

PTMC, papillary thyroid microcarcinoma; TSH, thyroid-stimulating hormone; ETE, extrathyroidal extension; TNM, tumor-node-metastasis; $\mathrm{SD}$, standard deviation.

Association of IF with clinical parameters. The details and clinical characteristics of all patients included in the present study are presented in Table I. Older patients ( $\geq 45$ years) had a significantly increased incidence of IF $(\mathrm{P}=0.012)$ compared with patients $<45$ years. In addition, significantly more females presented with IF $(\mathrm{P}=0.024)$ compared with males that 
Table II. Association between interstitial fibrosis and common biomarkers using the $\chi^{2}$ text.

\begin{tabular}{|c|c|c|c|c|}
\hline Biomarkers & Fibrosis-present (\%) & Fibrosis-absent (\%) & Total & P-value \\
\hline \multicolumn{5}{|l|}{ p53 } \\
\hline Positive & $161(63.39)$ & $105(63.64)$ & 266 & \multirow[t]{3}{*}{0.9587} \\
\hline Negative & $93(36.61)$ & $60(36.36)$ & 153 & \\
\hline Total & 254 & 165 & 419 & \\
\hline \multicolumn{5}{|l|}{ Ki67 } \\
\hline Positive & $184(54.12)$ & $107(62.57)$ & 291 & \multirow[t]{3}{*}{0.0685} \\
\hline Negative & $156(45.88)$ & $64(37.43)$ & 220 & \\
\hline Total & 340 & 171 & 511 & \\
\hline \multicolumn{5}{|l|}{ CK19 } \\
\hline Positive & $316(93.49)$ & $145(86.31)$ & 461 & \multirow[t]{3}{*}{0.0075} \\
\hline Negative & $22(6.51)$ & 23 (13.69) & 45 & \\
\hline Total & 338 & 168 & 506 & \\
\hline \multicolumn{5}{|l|}{$\mathrm{Tg}$} \\
\hline Positive & $268(82.72)$ & $133(82.10)$ & 401 & \multirow[t]{3}{*}{0.8658} \\
\hline Negative & $56(17.28)$ & $29(17.90)$ & 85 & \\
\hline Total & 324 & 162 & 486 & \\
\hline \multicolumn{5}{|l|}{ TTF-1 } \\
\hline Positive & $296(88.36)$ & $137(83.54)$ & 433 & \multirow[t]{3}{*}{0.8659} \\
\hline Negative & 39 (11.44) & 27 (16.59) & 66 & \\
\hline Total & 335 & 164 & 499 & \\
\hline \multicolumn{5}{|l|}{ Galectin-3 } \\
\hline Positive & $293(88.25)$ & $159(94.08)$ & 452 & \multirow[t]{3}{*}{0.0220} \\
\hline Negative & $39(11.75)$ & $9(5.33)$ & 48 & \\
\hline Total & 332 & 168 & 500 & \\
\hline
\end{tabular}

CK, cytokeratin; TTF-1, thyroid transcription factor I; Tg, thyroglobulin; p53, cellular tumor antigen p53; Ki-67, proliferation marker protein Ki-67.

A

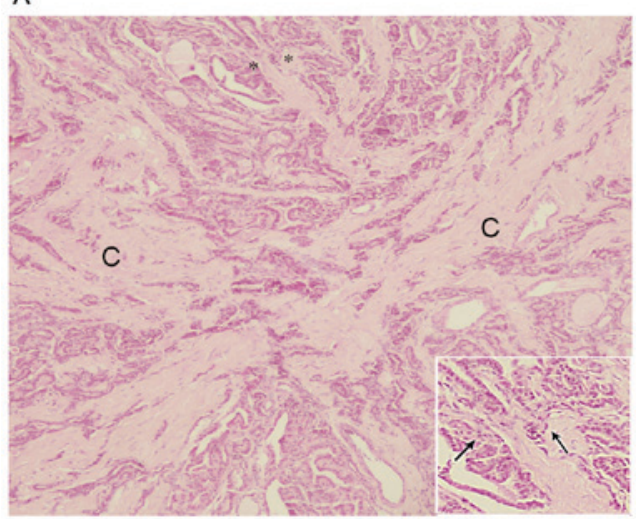

B

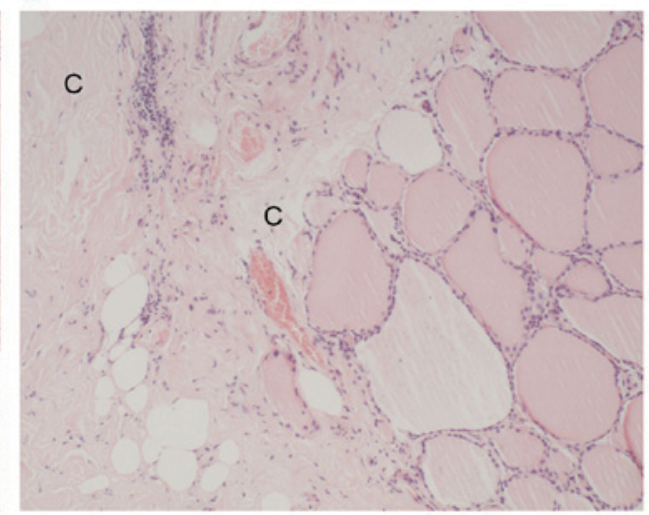

Figure 1. Stained images of PTMC and nodular goiter with IF. (A) A PTMC tissue section was stained with H\&E. There are numerous fibroblasts in the tissue and they are spindle like and adjacent to the papillary carcinoma cells as demonstrated by the asterisks. In the lower right of the image, the asterisk area is enlarged and the arrows indicate the fibroblasts. The pink fiber with few nucleuses is collagen as indicated by the area of the letter C. (B) H\&E staining of nodular goiter with IF for comparison with the PTMC tissue. Diffuse collagen fibers appear next to the nodular goiter and there is almost no fibroblast proliferation. The letter $\mathrm{C}$ indicates the area of collagen fiber. Magnification, x100. PTMC, papillary thyroid microcarcinoma; IF, interstitial fibrosis; H\&E, hematoxylin and eosin.

presented with IF. The median tumor size was $5.0 \mathrm{~mm}$ (range, $1.0-10 \mathrm{~mm}$ ). Using the median size as the cut-off point, a tumor $\geq 5.0 \mathrm{~mm}$ was revealed to be associated with a significantly increased possibility of fibrotic formation compared with PTMC without IF $(\mathrm{P}=0.017)$. Fibrosis was revealed to be significantly associated with lymph node metastasis 


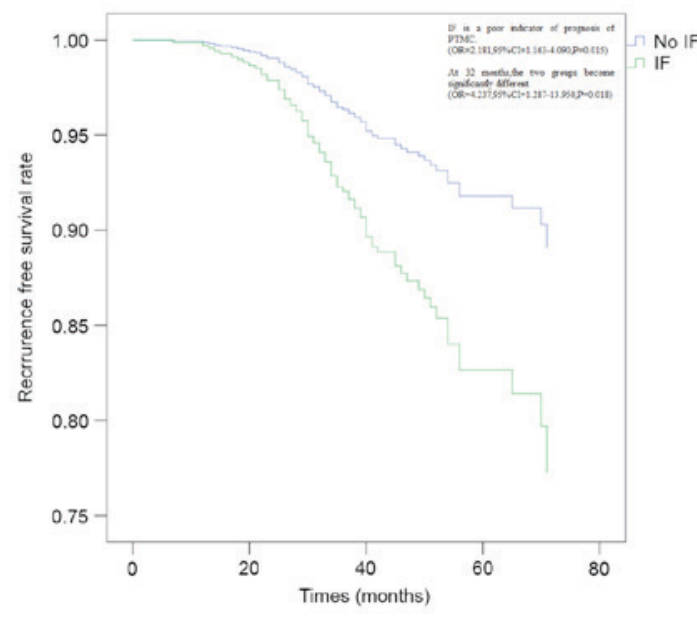

Figure 2. Cox survival rate. The recurrence-free survival rate of PTMC with IF is increased compared with that of PTMC without IF (hazard ratio $=2.181$; $95 \%$ confidence interval $=1.163-4.090 ; \mathrm{P}=0.015)$. At 32 months, the 2 groups begin to become significantly different (hazard ratio $=4.237 ; 95 \%$ confidence interval $=1.287-13.950 ; \mathrm{P}=0.018)$. $\mathrm{PTMC}$, papillary thyroid microcarcinoma; IF, interstitial fibrosis.

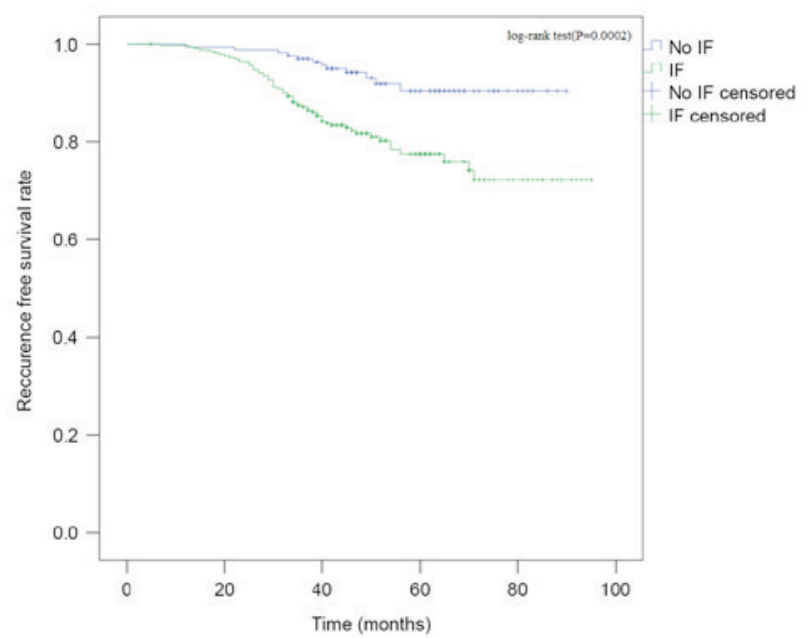

Figure 3. Kaplan-Meier curve of survival rate. The curves describe the recurrence-free survival rates of papillary thyroid microcarcinoma with and without interstitial fibrosis. Calculated using the log-rank test $(\mathrm{P}=0.0002)$.

$(\mathrm{P}=0.0003)$. However, there was no significant association between calcification, serum TSH levels, tumor multiplicity, bilaterality, ETE or subtype of PTMC and IF.

Association of IF with pathological biomarkers. Common biomarkers were observed and analyzed to determine whether they were associated with the presence of IF in tumors. Galectin-3 and CK19 revealed a significant association with IF $(\mathrm{P}=0.022$ and $\mathrm{P}=0.008$, respectively; Table II). There were no other significant associations observed between the presence of Tg, TTF-1, p53or Ki67 and the cases of IF.

Results of survival data. Due to the decreased mortality rate of patients with PTMC, and since only 4 patients suffered mortality during the follow-up period, recurrence-free survival was used as the outcome of interest. A lack of recurrence outcome due to a lack of follow-up, loss to the follow-up
Table III. Risk factors of PTMC recurrence by Cox's proportional hazard model.

\begin{tabular}{lccr}
\hline Variable & $\begin{array}{c}\text { Odds } \\
\text { ratio }\end{array}$ & $\begin{array}{c}95 \% \text { confidence } \\
\text { interval }\end{array}$ & P-value \\
\hline Sex & 1.656 & $1.001-2.739$ & 0.049 \\
Age (>45 years) & 0.483 & $0.198-1.180$ & 0.110 \\
Multiplicity & 1.758 & $0.628-4.922$ & 0.283 \\
Bilaterality & 3.735 & $2.261-6.169$ & $<0.001$ \\
ETE & 1.289 & $0.793-2.094$ & 0.305 \\
IF & 2.227 & $1.186-4.181$ & 0.013 \\
Lymph metastasis & 3.560 & $2.164-5.858$ & $<0.001$ \\
\hline
\end{tabular}

PTMC, papillary thyroid microcarcinoma; ETE, extrathyroidal extension; IF, interstitial fibrosis.

period and non-thyroid-cancer mortality was defined as censored data. The censoring rate was 93.0 and $81.2 \%$ in the IF and no IF groups, respectively. The number of loss to follow-up period patients was 33 in the IF group and 52 in the no IF group. Each group had 1 patient who suffered from non-thyroid-cancer mortality. The median follow-up time was 46 months (range, 5.0-90 months) and the total recurrence rate was $14.87 \%$ (76 cases). The fibrosis group demonstrated an $18.82 \%$ (64 cases) recurrence rate and the no-fibrosis group had a $7.02 \%$ (12 cases) recurrence rate. Multivariate analysis by Cox's proportional hazard model revealed that the presence of IF (hazard ratio $=2.18195 \%$; confidence interval $=1.163-4.090$; $\mathrm{P}=0.015$ ) was an independent factor for the prediction of a poor prognosis in patients with PTMC (Fig. 2).

Kaplan-Meier survival curves revealed the same outcome (log rank, $\mathrm{P}=0.002$ ) (Fig. 3). At 32 months, the two groups become significantly different as analyzed by Cox's proportional hazard model (hazard ratio $=4.23795 \%$; confidence interval $=1.287-13.950 ; \mathrm{P}=0.018)$. Other poor prognostic indicators as presented in Table III were age ( $>45$ years; $\mathrm{P}=0.49)$, extrathyroidal extension $(\mathrm{P}<0.001)$ and lymphocytic metastasis $(\mathrm{P}<0.001)$. Therefore, IF is a poor indicator of prognosis of PTMC.

\section{Discussion}

Cancer-associated fibroblasts have been described in multiple types of cancer; they appear primarily as abnormal IF and have been extensively studied (27-30). Fibrotic density, when there are no superior clear parameters, may be considered as a vital index of prognosis (24), however, few previous studies have focused on the correlation between IF and PTMC (31) and to the best of our knowledge the association between fibrosis and specific biomarkers has not been previously reported.

IF has not been clearly defined within the medical community. In general, IF is considered to occupy the central section of the tumor and often consists of radiating and expanding fibrous bands (32). Rebecchini et al (33) revealed that a characteristic feature of PTC was that interstitial fibers occupied $40-60 \%$ of the central section of the tumors. In a study performed by Isarangkul (24), 33 of 37 PTC specimens 
presented interstitial changes consisting of dense collagen and fibroblasts. It was suggested that PTC was significantly associated with fibrosis when compared with the follicular subtype (odds ratio $=37.95 ; \mathrm{P}<0.01$ ). It is clear that there are correlations between tumorigenesis and fibrosis in many tumors, including breast, ovarian, esophageal, colorectal, pancreatic and prostate cancers (16-20). Interstitial changes influence tumor infiltration, metastasis, prognosis and neovascularization (34). In the present study observations under a light microscope demonstrated that the majority of IF cases were accompanied by an incomplete fibrotic boundary of the tumor, as with the fibrosis from the central section of the tumor, which disturbs the formation of the fiber encapsulation on the tumor. It was also revealed that IF is a poor indicator of prognosis; therefore, the formation of fibrotic lesions may be referred to as a more aggressive behavior of the tumor.

In the present study, tumors with fibrosis were significantly associated with a patient's age $(\mathrm{P}=0.0331)$ and tumor size $(\mathrm{P}=0.0166)$, as previously reported (35). Female patients were more likely to have fibrotic changes compared with male patients. Whether an estrogen receptor (ER) wound contributed to this change requires further study. It has been previously reported that fibrotic focus has an association with ERs in breast cancer (34).

Although certain previous studies have considered that the grade of IF may predict tumor recurrence and metastasis (34), there is little evidence for this in thyroid carcinoma. However, De Matos et al (36) detected the expression of galectin-3 in three types of thyroid tissue, the results of which revealed that the expression ratios in 84 cases of PTC and 38 follicular carcinoma cases were 72.6 and $21.0 \%$, respectively, whereas it was nearly zero in non-tumor cases. Additionally, galection-3 is considered as serving a key role in cellular adhesion and interactions between cells and their matrix, which may reflect tumor metastasis conditions (37). Certain previous studies have reported that galectin-3 may be viewed as a potential tumor marker of metastasis and poor prognosis (3). In the present study, it was revealed that a higher expression level of galectin-3 was significantly associated with fibrosis formation. Therefore, patients who are galectin-3 positive with PTMC with IF may be considered as evidence that the formation of IF predicts prognosis, alternatively IF formation may be as a result of the expression of galectin-3. Given the difficulties of diagnosing thyroid tumors, specimens stained to determine IF and the expression of galectin-3 may increase the sensitivity and specificity of a diagnosis and the prediction of a prognosis, particularly when PTMC is determined.

It was previously reported that the expression of CK19 was decreased in normal thyroid tissue; however, CK19 may be viewed as a vital biomarker for cancer when carcinoma cells of PTMC are positive, compared with normal thyroid tissue (38). Although there has been no evidence that CK-19 is a predictor of prognosis, the association between IF and CK19 is positive in the present study, it also can be speculated that the IF has an effect on the PTMC, additional studies are required to determine the association between IF and CK19.

To conclude, it was revealed that there is an association between IF and PTMC, how the underlying mechanism behind this association remains unclear. The present study demonstrated that IF combined with specific biomarkers may be an important diagnostic tool for PTMC. Additional studies are required to determine the course of the development of IF and whether it is associated with tumorigenesis and prognosis.

\section{Acknowledgements}

The authors would like to thank the staff, particularly Professor Yuchen Han at the Institute of Pathology of China Medical University for advice and support.

\section{References}

1. Kammori M, Fukumori T, Sugishita Y, Hoshi M and Yamada T: Therapeutic strategy for low-risk thyroid cancer in Kanaji Thyroid Hospital. Endocr J 61: 1-12, 2014.

2. Roti E, Rossi R, Trasforini G, Bertelli F, Ambrosio MR, Busutti L, Pearce EN, Braverman LE and Degli Uberti EC: Clinical and histological characteristics of papillary thyroid microcarcinoma: Results of a retrospective study in 243 patients. J Clin Endocrinol Metab 91: 2171-2178, 2006.

3. Tang W, Huang C, Tang C, Xu J and Wang H: Galectin-3 may serve as a potential marker for diagnosis and prognosis in papillary thyroid carcinoma: A meta-analysis. Onco Targets Ther 9: 455-460, 2016.

4. Isic Dencic T, Cvejic D, Paunovic I, Tatic S, Havelka M and Savin S: Cytokeratin19 expression discriminates papillary thyroid carcinoma from other thyroid lesions and predicts its aggressive behavior. Med Oncol 30: 362, 2013.

5. Haugen BR, Alexander EK, Bible KC, Doherty GM, Mandel SJ, Nikiforov YE, Pacini F, Randolph GW, Sawka AM, Schlumberger M, et al: 2015 American thyroid association management guidelines for adult patients with thyroid nodules and differentiated thyroid cancer: The American Thyroid association guidelines task force on thyroid nodules and differentiated thyroid cancer. Thyroid 26: 1-133, 2016.

6. Pacini F: Thyroid microcarcinoma. Best Pract Res Clin Endocrinol Metab 26: 421-429, 2012.

7. Giannini R, Faviana P, Cavinato T, Elisei R, Pacini F, Berti P, Fontanini G, Ugolini C, Camacci T, De Ieso K, et al: Galectin-3 and oncofetal-fibronectin expression in thyroid neoplasia as assessed by reverse ranscription-polymerase chain reaction and immunochemistry in cytologic and pathologic specimens. Thyroid 13: 765-770, 2003.

8. Cheung CC, Ezzat S, Freeman JL, Rosen IB and Asa SL: Immunohistochemical diagnosis of papillary thyroid carcinoma. Mod Pathol 14: 338-342, 2001.

9. Kreft A, Hansen T and Kirkpatrick CJ: Thyroid transcription factor 1 expression in cystic lesions of the neck: An immunohistochemical investigation of thyroglossal duct cysts, branchial cleft cysts and metastatic papillary thyroid cancer. Virchows Arch 447: 9-11, 2005.

10. McLeod DS, Sawka AM and Cooper DS: Controversies in primary treatment of low-risk papillary thyroid cancer. Lancet 381: 1046-1057, 2013.

11. Patron V, Bedfert C, Le Clech G, Aubry K and Jegoux F: Pattern of lateral neck metastases in N0 papillary thyroid carcinoma. BMC Cancer 11: 8, 2011.

12. Hartl DM, Leboulleux S, Al Ghuzlan A, Baudin E, Chami L, Schlumberger M and Travagli JP: Optimization of staging of the neck with prophylactic central and lateral neck dissection for papillary thyroid carcinoma. Ann Surg 255: 777-783, 2012.

13. Pazaitou-Panayiotou K, Capezzone M and Pacini F: Clinical features and therapeutic implication of papillary thyroid microcarcinoma. Thyroid 17: 1085-1092, 2007.

14. Chow SM, Law SC, Chan JK, Au SK, Yau S and Lau WH: Papillary microcarcinoma of the thyroid-prognostic significance of lymph node met astasis and multifocality. Cancer 98: 31-40, 2003.

15. Kim TY, Hong SJ, Kim JM, Kim WG, Gong G, Ryu JS, Kim WB, Yun SC and Shong YK: Prognostic parameters for recurrence of papillary thyroid microcarcinoma. BMC Cancer 8: 296, 2008.

16. Fisher ER, Palekar AS, Sass R and Fisher B: Scar cancers: Pathologic findings from the national surgical adjuvant breast project (protocol no. 4)-IX. Breast Cancer Res Treat 3: 39-59, 1983. 
17. Zhang C, Fu L, Fu J, Hu L, Yang H, Rong TH, Li Y, Liu H, Fu SB, Zeng YX and Guan XY: Fibroblast growth factor receptor 2-positive fibroblasts provide a suitable microenvironment for tumor development and progression in esophageal carcinoma. Clin Cancer Res 15: 4017-4027, 2009.

18. Hwang RF, Moore T, Arumugam T, Ramachandran V, Amos KD, Rivera A, Ji B, Evans DB and Logsdon CD: Cancer-associated stromal fibroblasts promote pancreatic tumor progression. Cancer Res 68: 918-926, 2008.

19. Kozel PJ, Friedman RA, Erway LC, Yamoah EN, Liu LH, Riddle T, Duffy JJ, Doetschman T, Miller ML, Cardell EL and Shull GE: Balance and hearing deficits in mice with a null mutation in the gene encoding plasma membrane $\mathrm{Ca}^{2+}$-ATPase isoform. J Bio Chem 273: 18693-18696, 1998.

20. Nazareth MR, Broderick L, Simpson-Abelson MR, Kelleher RJ Jr, Yokota SJ and Bankert RB: Characterization of human lung tumor-associated fibroblasts and their ability to modulate the activation of tumor-associated T cells. J Immunol 178: 5552-5562, 2007.

21. Kondo T, Okabayashi K, Hasegawa H, Tsuruta M, Shigeta K and Kitagawa Y: The impact of hepatic fibrosis on the incidence of liver metastasis from colorectal cancer. Br J Cancer 115: 34-39, 2016.

22. Chen X, Xiao W, Chen W, Liu X, Wu M, Bo Q, Luo Y, Ye S, Cao Y and Liu Y: MicroRNA-26a and -26b inhibit lens fibrosis and cataract by negatively regulating Jagged-1/Notch signaling pathway. Cell Death Differ 24: 1431-1442, 2017.

23. Miura K, Hamanaka K, Koizumi T, Kitaguchi Y, Terada Y, Nakamura D, Kumeda H, Agatsuma H, Hyogotani A, Kawakami S, et al: Clinical significance of preoperative serum albumin level for prognosis in surgically resected patients with non-small cell lung cancer: Comparative study of normal lung, emphysema, and pulmonary fibrosis. Lung Cancer 111: 88-95, 2017.

24. Isarangkul W: Dense fibrosis. Another diagnostic criterion for papillary thyroid carcinoma. Arch Pathol Lab Med 117: 645-666, 1993.

25. Livolsi VA and Saavedra JA: Papillary carcinoma. In: DeLellis RA, Lloyd RV, Heitz PU and Eng C (eds). World Health Organization Classification of Tumours: Pathology and Genetics of Tumours of Endocrine Organs. Vol 8. IARC Press, Lyon, France, pp57-66, 2004.

26. Edge SB and Compton CC: The American Joint Committee on Cancer: The 7th edition of the AJCC cancer staging manual andthe future of TNM. Ann Surg Oncol 17: $1471-1474,2010$

27. Kumar V, Donthireddy L, Marvel D, Condamine T, Wang F, Lavilla-Alonso S, Hashimoto A, Vonteddu P, Behera R, Goins MA, et al: Cancer-associated fibroblasts neutralize the anti-tumor effect of CSF1 receptor blockade by inducing PMN-MDSC infiltration of tumors. Cancer Cell 32: 654-668.e5, 2017.

28. Sewell-Loftin MK, Bayer SVH, Crist E, Hughes T, Joison SM, Longmore GD and George SC: Cancer-associated fibroblasts support vascular growth through mechanical force. Sci Rep 7 : $12574,2017$.
29. Pang T, Wang X, Gao J, Chen W, Shen XJ, Nie MM, Luo T, Yin K, Fang G, Wang KX and Xue XC: Fiber-modified hexon-chimeric oncolytic adenovirus targeting cancer associated fibroblasts inhibits tumor growth in gastric carcinoma. Oncotarget 8: 76468-76478, 2017.

30. Tao L, Huang G, Song H, Chen Y and Chen L: Cancer associated fibroblasts: An essential role in the tumor microenvironment. Oncol Lett 14: 2611-2620, 2017.

31. Zhang J, Wang Y, Li D and Jing S: Notch and TGF- $\beta / S \operatorname{mad} 3$ pathways are involved in the interaction between cancer cells and cancer-associated fibroblasts in papillary thyroid carcinoma. Tumour Biol 35: 379-385, 2014.

32. Van den Eynden GG, Colpaert CG, Couvelard A, Pezzella F, Dirix LY, Vermeulen PB, Van Marck EA and Hasebe T: A fibrotic focus is a prognostic factor and a surrogate marker for hypoxia and (lymph)angiogenesis in breast cancer: Review of the literature and proposal on the criteria of evaluation. Histopathology 51: 440-451, 2007.

33. Rebecchini C, Nobile A, Piana S, Sarro R, Bisig B, Gerasimos SP, Saglietti C, Matter M, Marino L and Bongiovanni M: Papillary thyroid carcinoma with fibromatosis-like stroma: Are port of two cases. Endocr Pathol 13: 219-221, 2002.

34. Mujtaba SS, Ni YB, Tsang JY, Chan SK, Yamaguchi R, Tanaka M, Tan PH and Tse GM: Fibrotic focus in breast carcinomas: Relationship with prognostic parameters and biomarkers. Ann Surg Oncol 20: 2842-2849, 2013.

35. Zhou H, Kimura K, Orita T, Nishida T and Sonoda KH: Inhibition by female sex hormones of collagen degradation by corneal fibroblasts. Mol Vis 17: 3415-422, 2011.

36. De Matos PS, Ferreira AP, de Oliveira Facuri F, Assumpção LV, Metze K and Ward LS: Usefulness of HBME-1, cytokeratin 19 and galectin-3 immunostainingin the diagnosis of thyroid malignancy. Histopathology 47: 391-401, 2005.

37. Htwe TT, Karim N, Wong J, Jahanfar S and Mansur MA: Differential expression of galectin-3 in advancing thyroid cancer cells: A clue toward understanding tumour progression and metastasis. Singapore Med J 51: 856-859, 2010.

38. Erkılıç S, Aydın A and Koçer NE: Diagnostic utility of cytokeratin 19 expression in multinodular goiter with papillary areas and papillary carcinoma of thyroid. Endocr Pathol 13: 207-211, 2002.

This work is licensed under a Creative Commons Attribution-NonCommercial-NoDerivatives 4.0 International (CC BY-NC-ND 4.0) License. 